Proceedings of the International Symposium on Physics of Materials (ISPMA 14), September 10-15, 2017, Prague

\title{
Effect of Cold Rolling on Precipitation Processes in $\mathrm{Al}-\mathrm{Zn}-\mathrm{Mg}(-\mathrm{Sc}-\mathrm{Zr})$ Alloy
}

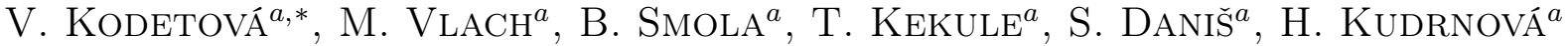 \\ AND J. MÁLEK ${ }^{b}$ \\ ${ }^{a}$ Charles University, Faculty of Mathematics and Physics, Ke Karlovu 3, 12116 Prague, Czech Republic \\ ${ }^{b}$ Czech Technical University in Prague, Faculty of Mechanical Engineering, \\ Karlovo namesti 13, 12135 Prague, Czech Republic
}

\begin{abstract}
The effect of cold rolling ( $6 \%$ and $21 \%$ ) on electrical, mechanical and thermal properties and microstructure of the classical mould-cast $\mathrm{Al}-\mathrm{Zn}-\mathrm{Mg}$ alloy with and without $\mathrm{Sc}, \mathrm{Zr}$-addition were studied. Samples were isochronally annealed up to $460{ }^{\circ} \mathrm{C}$. Electrical resistivity and microhardness together with differential scanning calorimetry measurements were compared to microstructure development. The initial microhardness values of the alloys reflect the deformation degree. Distinct changes in electrical resistivity as well as in heat flow of the alloys studied are mainly caused by dissolution of Zn,Mg-rich Guinier-Preston zones and subsequent precipitation of the metastable $\eta^{\prime}$ phase. Precipitation of this phase is responsible for a slight hardening effect. Probably an easier diffusion of $\mathrm{Zn}$ and $\mathrm{Mg}$ atoms along dislocations in the cold-rolled alloys is responsible for the dissolution of the Guinier-Preston zones and precipitation of the $\mathrm{Zn}, \mathrm{Mg}$-containing particles at the relatively lower temperatures in comparison to classical mould-cast alloys. Microstructure observation proved that the Sc,Zr-content is mainly concentrated in randomlylocalized regions in the $\mathrm{Al}$ matrix and together with $\mathrm{Zn}$ and $\mathrm{Mg}$ in the particles at grain boundaries. The hardening effect after annealing above $280^{\circ} \mathrm{C}$ was observed in the AlZnMgScZr alloy. Microhardness decrease at temperatures above $\approx 350^{\circ} \mathrm{C}$ in the alloys without $\mathrm{Sc}$ and $\mathrm{Zr}$ is probably connected with faster recovery processes. Cold rolling has no significant effect on the apparent activation energy values of the Guinier-Preston zones dissolution and formation of the $\mathrm{Zn}, \mathrm{Mg}$-containing particles.
\end{abstract}

DOI: 10.12693/APhysPolA.134.631

PACS/topics: 81.30.Mh, 81.40.Cd, 84.37.+q, 68.37.Lp

\section{Introduction}

The Al-based alloys are widely used in aircraft and aero-vehicle structural components [1]. The commercial Al-Zn-Mg-based alloys (AA7xxx series) exhibit reasonable solid solution hardening [2-8]. The decomposition of the supersaturated solid solution can be described as: SSS (supersaturated solid solution) $\rightarrow$ GP zones (Zn, $\mathrm{Mg}) \rightarrow$ metastable $\eta^{\prime}$ phase (hexagonal structure) $\rightarrow$ stable $\eta$ phase $\left(\mathrm{MgZn}_{2}\right.$, hexagonal structure) [2-8]. The mechanical properties logically depend on chemical composition of the alloys (mainly on $\mathrm{Zn}$ - and Mg-content) as well as on thermomechanical treatment and then the decomposition sequence could be more complicated [29]. The decomposition sequence should also contain metastable semicoherent $T^{\prime}$ phase $\left(\mathrm{Al}_{2} \mathrm{Zn}_{3} \mathrm{Mg}_{3}\right.$ - hexagonal structure) and equilibrium $T$ phase $\left(\mathrm{Al}_{2} \mathrm{Zn}_{3} \mathrm{Mg}_{3}-\right.$ cubic structure), too $[8,10,11]$. Yang et al. [8] reported that an $\mathrm{Al}-7.60 \mathrm{Zn}-2.55 \mathrm{Mg}$ (wt.\%) alloy with a characteristically high $\mathrm{Mg} / \mathrm{Zn}$ mole ratio can be strengthened by the $T$-phase precipitates.

Generally, the addition of Sc can effectively improve strength, refine grains and inhibit recrystallization [1]. To reduce the cost, $\mathrm{Zr}$ is added with $\mathrm{Sc}$ to reach compa-

*corresponding author; e-mail: veronika.kodetova@seznam.cz rable mechanical properties obtained from Sc content [1]. The improvements of these properties are owing to the formation of the $\mathrm{Al}_{3}(\mathrm{Sc}, \mathrm{Zr})$ particles with $L 1_{2}$ structure $[1,12,13]$. The $\mathrm{Al}_{3}(\mathrm{Sc}, \mathrm{Zr})$ phase is stable at higher temperatures than binary $\mathrm{Al}_{3} \mathrm{Sc}$ or $\mathrm{Al}_{3} \mathrm{Zr}$ phase and has significant hardening effect [1]. Despite of several works (e.g. Refs. $[1,4,5])$ the influence of rolling on the precipitation processes in the $\mathrm{Al}-\mathrm{Zn}-\mathrm{Mg}-\mathrm{Sc}-\mathrm{Zr}$-based alloys was not studied in detail.

In the present study the effect of cold rolling on precipitation processes in the $\mathrm{Al}-\mathrm{Zn}-\mathrm{Mg}$-based alloys with and without Sc,Zr-addition was studied. The results of resistivity changes and microhardness response to the isochronal annealing and thermal changes were compared to the microstructure development.

\section{Experimental details}

Two mould-cast (MC) $\mathrm{Al}-5.34 \mathrm{wt} . \% \mathrm{Zn}-3.18 \mathrm{wt} . \% \mathrm{Mg}$ - 0.05wt.\%Mn - 0.03wt. $\% \mathrm{Fe}, \mathrm{Si}(\mathrm{AlZnMg})$ and $\mathrm{Al}-$ $5.3 \mathrm{wt} . \% \mathrm{Zn}-3.2 \mathrm{wt} . \% \mathrm{Mg}-0.2 \mathrm{wt} . \% \mathrm{Sc}-0.1 \mathrm{wt} . \% \mathrm{Zr}-$ 0.06wt.\% Mn - 0.04wt.\% Fe,Si (AlZnMgScZr) alloys were studied. Both alloys were cold-rolled with reduction $6 \%$ (CR6) and 21\% (CR21) and samples were isochronally annealed up to $460^{\circ} \mathrm{C}$.

The relative electrical resistivity changes $\Delta \rho / \rho_{0}$ were determined at $78 \mathrm{~K}$ within an accuracy of $10^{-4}$ by means of the DC four-point method. The influence of parasitic thermoelectromotive force was suppressed by cur- 
rent reversal. The influence of isochronal annealing on mechanical properties was studied using the Vickers microhardness (HV) measured at room temperature (RT). The samples were kept in liquid nitrogen between measurements to preserve the microstructure developed during the annealing. Samples for resistivity and microhardness measurements were studied during the isochronal annealing procedure which was performed exactly in the same way as described in Refs. [12, 13]. The thermal behaviour of the alloys was studied using differential scanning calorimetry (DSC) performed at heating rates of 1 , 2, 5, 10, 20 and $30 \mathrm{~K} / \mathrm{min}$ in the Netzsch DSC $204 \mathrm{~F} 1$ Phoenix apparatus. A specimen of mass between 10 and $20 \mathrm{mg}$ was placed in $\mathrm{Al}_{2} \mathrm{O}_{3}$ crucibles in a dynamic nitrogen atmosphere $(40 \mathrm{ml} / \mathrm{min})$.

The measurements mentioned above were compared to microstructure development observed by optical microscopy, transmission electron microscopy (TEM) and scanning electron microscopy (SEM). TEM and SEM observations were carried out in JEOL JEM 2000FX and MIRA I Schottky FE-SEMH microscopes to determine the microstructure of the alloys, respectively. The analysis of precipitated phases was complemented by energy-dispersive spectroscopy (EDS) performed by Xray BRUKER microanalyser. The specimens for TEM and SEM were annealed by the same procedure as those for the electrical resistivity.

\section{Results and discussion}

\subsection{As-prepared state of the alloys}

The initial values of resistivity $\mathrm{MC}$ alloys were calculated as $\approx 27 \mathrm{n} \Omega m$ for the AlZnMg alloy and $\approx 30 \mathrm{n} \Omega m$ for the AlZnMgScZr alloy, respectively. Higher initial value of the resistivity in the AlZnMgScZr alloy is probably caused by the Sc and Zr addition and also by higher content of the Mn and Fe (as detected by EDS). The initial microhardness values reflect the deformation degree in the cold-rolled alloys (see Fig. 1a and b).

SEM proved the $\mathrm{Zn}, \mathrm{Mg}$-containing eutectic phase at grain boundaries in the MC state of both alloys studied. It was also observed by TEM that the Sc,Zr-content in the initial state of the AlZnMgScZr alloy is not homogeneously distributed but concentrated in randomly localized matrix regions and together with $\mathrm{Zn}$ and $\mathrm{Mg}$ in the particles at grain boundaries. The grain size was observed as $\approx 20 \mu \mathrm{m}$ in both $\mathrm{MC}$ alloys. Only small amount of dislocations in grain interiors in the MC state of the alloys was observed by TEM. After cold rolling the amount of dislocations rapidly increase and dislocations decorated mainly grain boundaries - see Fig. 2. There were not observed any phases and/or particles (except mentioned eutectic phase) in the $\mathrm{MC}$ and $\mathrm{CR}$ alloys.

\subsection{Annealing of the alloys}

The response of microhardness changes (HV0.5) and relative resistivity changes $\Delta \rho / \rho_{0}$ measurements to stepby-step isochronal annealing of the mould-cast and coldrolled alloys are shown in Fig. 1. The HV0.5 values of

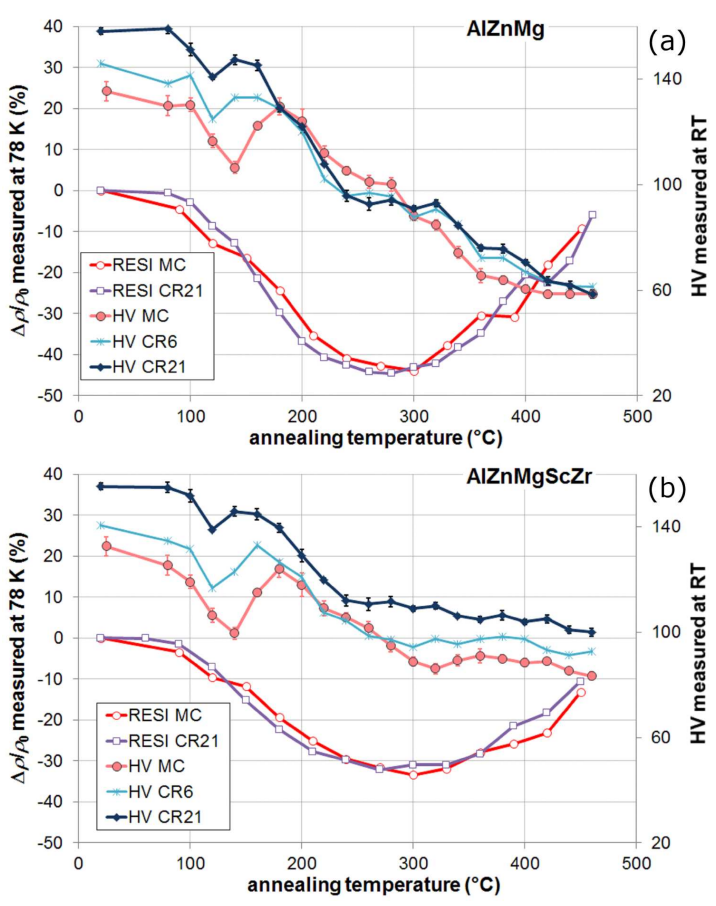

Fig. 1. Isochronal annealing curves of relative resistivity (measured at $78 \mathrm{~K}$ ) and microhardness HV0.5 changes (measured at RT) of the (a) AlZnMg alloys, (b) AlZnMgScZr alloys.

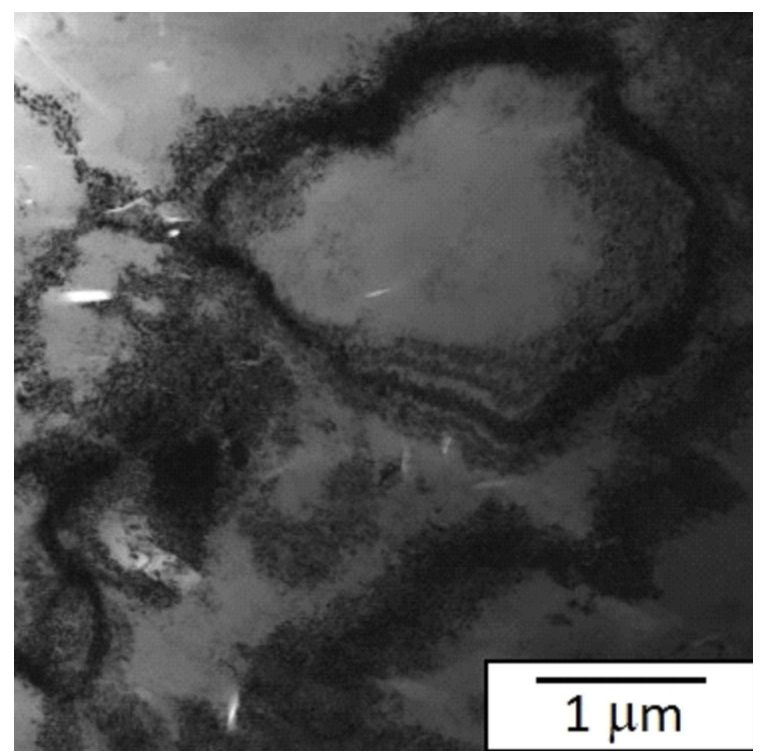

Fig. 2. TEM image of the CR21 AlZnMgScZr alloy in as-prepared state.

the alloys studied slowly decrease to a local minimum at $\approx 140-160^{\circ} \mathrm{C}$. After that the microhardness values increase to a maximum at $\approx 180-200^{\circ} \mathrm{C}$. The local minimum and local maximum of the microhardness values are shifted to lower temperatures in the cold-rolled alloys $\left(\approx 20^{\circ} \mathrm{C}\right)$. It can be seen that the Sc,Zr-addition has al- 
most no effect on microhardness changes up to $\approx 270^{\circ} \mathrm{C}$. But after that the HV0.5 values of the alloy without the $\mathrm{Sc}, \mathrm{Zr}$-addition continually decrease up to $460^{\circ} \mathrm{C}$ in contrast to the AlZnMgScZr alloy. Difference between microhardness values of the $\mathrm{AlZnMg}$ and $\mathrm{AlZnMgScZr}$ alloy is $\Delta \mathrm{HV} 0.5 \approx 22$ in the $\mathrm{MC}$ alloy and $\Delta \mathrm{HV} 0.5 \approx 40$ in the CR21 alloy. After annealing above $\approx 330^{\circ} \mathrm{C} \mathrm{mi-}$ crohardness values of the AlZnMgScZr alloy are almost constant and the influence of cold rolling is still obvious. Almost no differences of the microhardness values of $\mathrm{CR}$ and $\mathrm{MC}$ alloys are in the temperature range $200-460^{\circ} \mathrm{C}$ in the $\mathrm{AlZnMg}$ alloy.

The electrical resistivity curves show significant decrease of the $\Delta \rho / \rho_{0}$ to a minimum at $\approx 270-300{ }^{\circ} \mathrm{C}$ (see Fig. 1). Then the electrical resistivity increases for both alloys. One can see a small warp $\left(\right.$ at $\left.\approx 360^{\circ} \mathrm{C}\right)$ in the $\mathrm{MC}$ alloys which is followed by rapid increase of the relative resistivity up to the initial values. The fastest decrease of relative resistivity changes corresponds to the temperature interval of the hardening peak (at $\approx 180^{\circ} \mathrm{C}$ ). The relative resistivity changes are more pronounced in the alloy without Sc,Zr-addition.

Figure 3 shows the detail of the DSC curves of the MC and CR21 alloys at heating rate of $20 \mathrm{~K} / \mathrm{min}$ up to $300{ }^{\circ} \mathrm{C}$. Distinct endothermic process and exothermic process are observed in these curves up to $200^{\circ} \mathrm{C}$ in both studied alloys. The character of these processes agrees very well to DSC results observed in Refs. [6, 7, 11, 14]. Minima of the DSC peaks are shifted to lower temperatures by cold rolling which is probably caused by the easier diffusion of $\mathrm{Mg}$ and $\mathrm{Zn}$ atoms along dislocations.

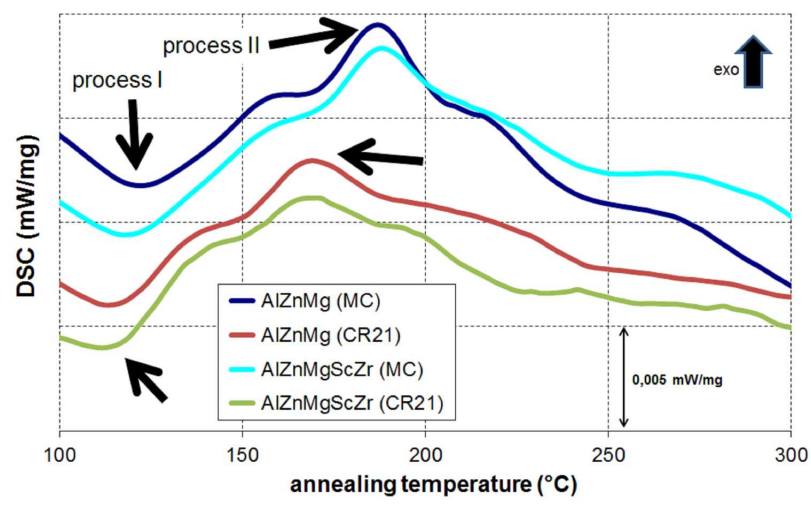

Fig. 3. DSC curves in linear heating rate $20 \mathrm{~K} / \mathrm{min}$ of the MC and CR2 1 alloys up to $300^{\circ} \mathrm{C}$.

It is generally known that the clusters and/or GP zones are formed in early stages of decomposition of solid solution in Al-based alloys. Ordinarily, these formations affect relative resistivity changes, (micro)hardness changes and heat flow observed by DSC measurements $[1,4-$ 7, 15]. From comparison of the isochronnal annealing curves up to $\approx 150{ }^{\circ} \mathrm{C}$ (see Fig. 1) it can be concluded that the GP zones are dissolved first. Dissolution of the GP zones leads to the resistivity and microhardness decrease. The first endothermic thermal effects (labeled as processes I) up to $\approx 150^{\circ} \mathrm{C}$ correspond to the dissolution of GP zones. The formation of the GP zones was probably done during the cooling of material after casting. One can also conclude that the Sc,Zr-addition does not significantly influence the formation and/or dissolution of the GP zones considering small concentration of the Sc,Zr dissolved in the matrix (because of the large amount of these additions is bounded in the $\mathrm{Zn}, \mathrm{Mg}$-rich particles around grain boundaries).

Figure 4 shows TEM image of the AlZnMgScZr CR21 alloy isochronally annealed up to $180^{\circ} \mathrm{C}$, where the $\eta^{\prime}$ phase particles can be seen. Thus the main resistivity decreases and microhardness increases in studied alloys (see Fig. 1) in the temperature range of $150-300^{\circ} \mathrm{C}$ and significant exothermic effect (process II) in the DSC curves (Fig. 3) is due to the precipitation of the metastable $\eta^{\prime}$-phase particles. In the $\mathrm{Al}-\mathrm{Zn}-\mathrm{Mg}(-\mathrm{Cu})$ alloys the metastable $\eta^{\prime}$ phase is typical hardening phase [2-9]. In the MC AlZnMg alloy $\eta^{\prime}$-phase particles were also observed after annealing up to $220^{\circ} \mathrm{C}$ [14]. The shift to lower temperatures in the CR21 alloys is caused by easier diffusion of $\mathrm{Mg}, \mathrm{Zn}$ atoms along dislocations in the cold-rolled alloys, again.

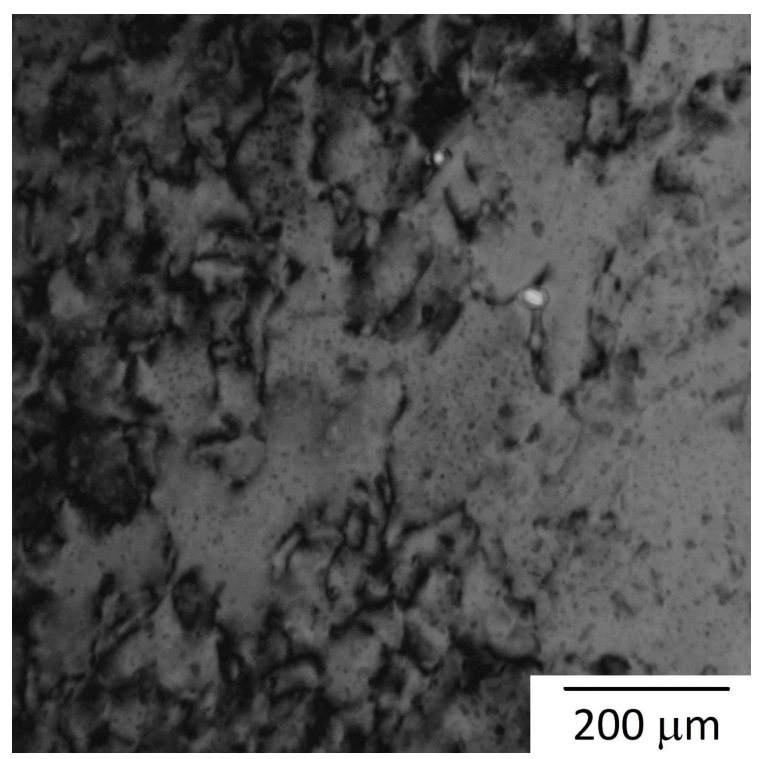

Fig. 4. TEM image of the AlZnMgScZr CR21 alloy annealed up to $180^{\circ} \mathrm{C}$.

From comparison of isochronal annealing curves of microhardness changes above $300{ }^{\circ} \mathrm{C}$ it can be concluded that the Sc,Zr-addition in the alloy has hardenable effect in the AlZnMgScZr alloys. The HV0.5 values of the alloy without the Sc,Zr-addition continually decrease up to $460{ }^{\circ} \mathrm{C}$ in contrast to the AlZnMgScZr alloy. Microhardness of the AlZnMgScZr MC and CR alloys shows almost no changes in the temperature range of $300-460^{\circ} \mathrm{C}$. After annealing up to $360^{\circ} \mathrm{C}$ two types of particles were observed by TEM in the AlZnMgScZr CR21 alloy. Small rods and large oval particles can be seen in Fig. 5. Rods 
are probably particles of the $\eta$ phase and ovals particles probably equilibrium $T$-phase $\left(\mathrm{Al}_{2} \mathrm{Zn}_{3} \mathrm{Mg}_{3}\right)$, as detected by EDS. In both MC alloys microstructure observation also proved presence of particles of the stable $\eta$ phase after annealing up to $360^{\circ} \mathrm{C}[14]$. Moreover, particles with $\mathrm{Mn}, \mathrm{Fe}$-content were observed in the MC AlZnMgScZr alloy $[1,4,13,14]$. The presence of these particles is probably connected with higher content of $\mathrm{Mn}$ and Fe addition in the alloy than in the AlZnMg alloy. Content of $\mathrm{Mn}$ and Fe is commonly present in the alloys of AA7xxx type $[1,8,9]$. Precipitation of both phases does not lead to the hardening and thermal changes in agreement with Refs. $[4,5,12,13]$. The particle precipitation of the stable $\eta$ - and $T$-phase and $\mathrm{Mn}, \mathrm{Fe}$-containing particles is probably the reason of the undulating of the resistivity curves at $\approx 360{ }^{\circ} \mathrm{C}$ (Fig. 1). Annealing above $390{ }^{\circ} \mathrm{C}$ probably led to the dissolution of the particles from the $\mathrm{Al}-\mathrm{Zn}-$ Mg system. Furthermore, the eutectic Zn,Mg-containing phase partly disappeared during the isochronal annealing above this temperature (as it was observed by SEM in MC alloys). These effects are probably connected with the resistivity increase above $\approx 360^{\circ} \mathrm{C}$.

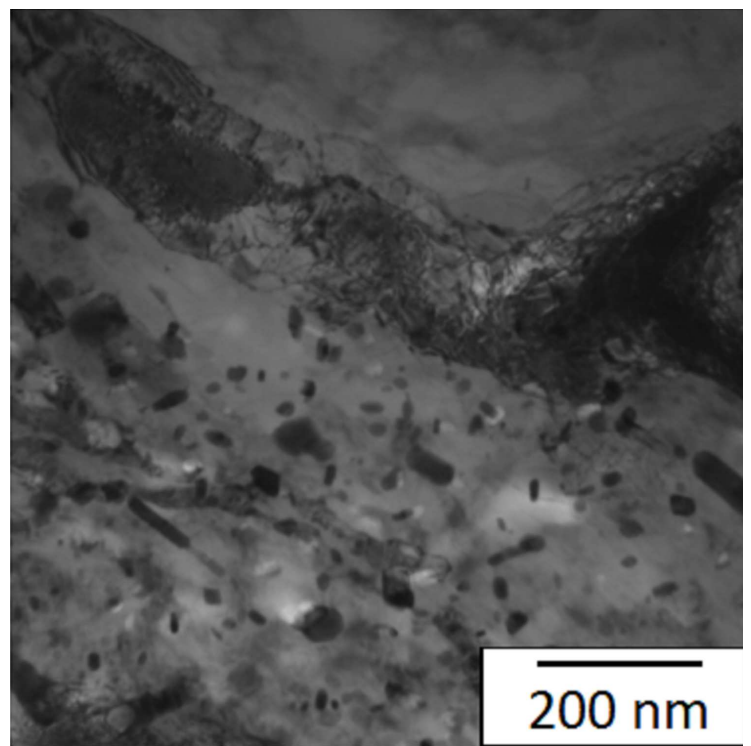

Fig. 5. TEM image of the AlZnMgScZr CR21 alloy annealed up to $360^{\circ} \mathrm{C}$.

\subsection{Thermal properties of the alloys}

On the basis of the obtained results, the apparent activation energies for individual processes (Fig. 6) by the Kissinger method [15] were calculated. The average activation energy of the dissolution of the GP zones in this work was calculated as $(106 \pm 15) \mathrm{kJ} / \mathrm{mol}$ for the CR21 alloys. The value of activation energy is higher than that for the GP zones formation $(\approx 60 \mathrm{~kJ} / \mathrm{mol}[3])$ in the $\mathrm{Al}-$ $\mathrm{Mg}-\mathrm{Zn}$-based alloys. The values of activation energies of the dissolution of the GP zones in the CR6 alloys are comparable to the MC and CR21 alloys. For a better recognition the values for the CR6 alloys were not plot to the Kissinger plot in Fig. 6. One can mention that the obtained activation energy values for the dissolution of GP zones is comparable to the diffusion activation energies of both $\mathrm{Zn}$ and $\mathrm{Mg}$ in $\mathrm{Al}$ of $\approx 120 \mathrm{~kJ} / \mathrm{mol} \mathrm{[3]}$.

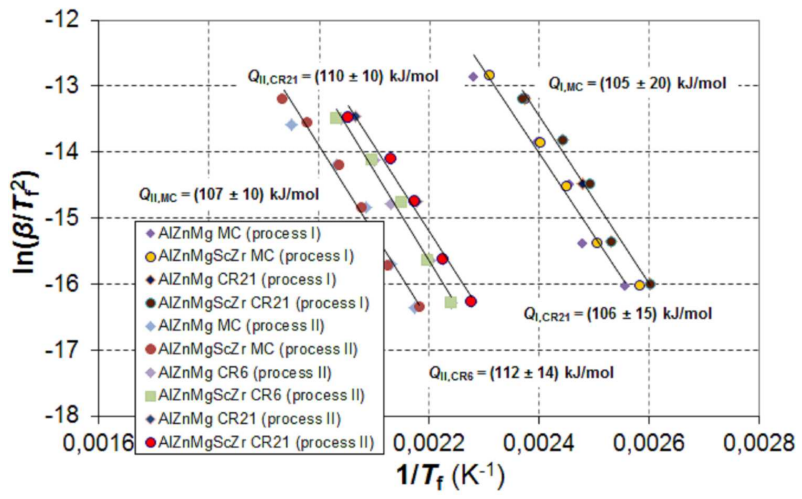

Fig. 6. Kissinger plot in the coordinate system of $\left[\ln \left(\beta / T_{f}^{2}\right) ; 1 / T_{f}\right]$ of the heat effects in the MC and CR alloys, $\beta$ is the linear heating rate; $T_{f}$ is the peak temperature of DSC trace for particular heat effects.

The average activation energy of the $\eta^{\prime}$-phase precipitation was calculated as $\approx 110 \mathrm{~kJ} / \mathrm{mol}$. The value agrees within accuracy with the apparent activation energy for precipitation of the $\eta^{\prime}$-phase $(80-100 \mathrm{~kJ} / \mathrm{mol})$ determined in the $\mathrm{Al}-\mathrm{Zn}-\mathrm{Mg}$-based alloys after ageing at various temperatures $[3,14]$. The temperature shifts of the maxima/minima of both mentioned processes (dissolution of the GP zones and precipitation of the $\eta^{\prime}$-phase) to the lower temperatures for the $\mathrm{CR}$ alloys in comparison to the MC alloys can be seen in Fig. 6 .

\section{Conclusions}

Results of characterization of the mould-cast and coldrolled alloys can be summarized in the following points:

- Microstructure observation proved the $\mathrm{Zn}, \mathrm{Mg}$ containing eutectic phase at grain boundaries in the alloys studied. Sc,Zr-content is mainly concentrated in randomly-localized regions in the $\mathrm{Al}$ matrix.

- The initial microhardness values of the alloys reflect the deformation degree. No effect of cold rolling to the microhardness changes in the $\mathrm{AlZnMg}$ alloy in the temperature interval $200-460{ }^{\circ} \mathrm{C}$ in contrary to AlZnMgScZr alloy was observed. The hardening effect after isochronal annealing at temperatures above $280^{\circ} \mathrm{C}$ was observed in the AlZnMgScZr alloy.

- The distinct changes in relative resistivity and microhardness isochronal curves as well as in heat flow 
of the alloys studied are mainly caused by the dissolution of the GP zones and precipitation of the metastable $\eta^{\prime}$-phase particles. The apparent activation energy values were observed regardless of cold rolling and Sc,Zr-addition as: dissolution of the GP zones $\approx 105 \mathrm{~kJ} / \mathrm{mol}$ and formation of the metastable $\eta^{\prime}$-phase $\approx 110 \mathrm{~kJ} / \mathrm{mol}$.

- Easier diffusion of $\mathrm{Zn}$ and Mg atoms along dislocations in the cold-rolled alloys is responsible for the dissolution of the GP zones and precipitation of the Zn,Mg-containing particles at the lower temperatures compared to the effects in classical mould-cast alloys.

\section{Acknowledgments}

This work was supported by The Czech Science Foundation (GACR, project no. 17-17139S).

\section{References}

[1] L.S. Toropova, D.G. Eskin, M.L. Kharakterova, T.V. Dobatkina, Advanced Aluminium Alloys Containing Scandium - Structure and Properties, Gordon and Breach, The Netherlands 1998.

[2] K.R. Prasanta, M.M. Ghosh, K.S. Ghosh, Mater. Charact. 104, 49 (2015).
[3] N. Afify, A. Gaber, G. Abbady, Mater. Sci. Appl. 2, 427 (2011).

[4] K.S. Ghosh, N. Gao, M.J. Starink, Mater. Sci. Eng. A 552, 164 (2012).

[5] K.S. Ghosh, N. Gao, Trans. Nonferrous Met. Soc. China 21, 1199 (2011).

[6] C. Antonione, F. Marino, G. Riontino, Mater. Chem. Phys. 20, 13 (1988).

[7] S. Abis, G. Riontino, Mater. Lett. 5, 442 (1987).

[8] X.B. Yang, J.H. Chen, J.Z. Liu, F. Qin, C.L. Wu, J. Alloys Comp. 610, 69 (2014).

[9] Ch. Cao, D. Zhang, Z. He, L. Zhuang, J. Zhang, Mater. Sci. Eng. A 666, 34 (2016).

[10] Ch. Feng, W. Shou, H. Liu, D. Yi, Y. Feng, Trans. Nonferrous Met. Soc. China 25, 3515 (2015).

[11] S. Gang, A. Cerezo, Acta Mater. 52, 4503 (2004).

[12] M. Vlach, J. Čížek, B. Smola, O. Melikhova, M. Vlček, V. Kodetová, H. Kudrnová, P. Hruška, Mater. Charact. 129, 1 (2017).

[13] M. Vlach, I. Stulíková, B. Smola, H. Císařová, J. Piešová, S. Daniš, R. Gemma, J. Málek, D. Tanprayoon, V. Neubert, Inter. J. Mater. Res. 103, 814 (2012).

[14] V. Kodetová, M. Vlach, B. Smola, J. Málek, T. Kekule, H. Kudrnová, in: METAL 2017, 26rd Int. Conf. on Metallurgy and Materials, Brno, Tanger Ltd, 2017, p. 1769.

[15] M.J. Starink, Thermochim. Acta 404, 163 (2003). 